Programa de Residência Pedagógica na Licenciatura em Informática: partilhando possibilidades

\title{
CONTRIBUIÇÕES DA ROBÓTICA PARA A EDUCAÇÃO BÁSICA: ENSINO, TECNOLOGIA E SOCIALIZAÇÃO
}

\author{
Laryssa Clemente Barbalho1, Alan Klinger Sousa Alves²
}

\section{PALAVRAS-CHAVE}

Robótica Educacional;

Tecnologia;

Socialização.

\section{RESUMO}

Com o crescente avanço da tecnologia e diante de uma sociedade informatizada, a robótica vem conquistando espaços significativos, principalmente no âmbito didático-pedagógico, não só por promover a interdisciplinaridade entre diferentes áreas do conhecimento, mas também, por contribuir nos processos de ensino e aprendizagem. Este capítulo tem por objetivo analisar a implementação de um projeto de robótica educacional na escola Estadual Manoel de Melo Montenegro de ensino integral, do município de Ipanguaçu/RN, considerando a constituição de práticas pedagógicas interdisciplinares e a participação ativa dos professores. A perspectiva é contribuir para o desenvolvimento de competências como raciocínio lógico, engajamento, relações interpessoais e intrapessoais, integração e conceitos aprendidos em diversas áreas do conhecimento. A utilização da robótica no âmbito educacional pode contribuir para o desenvolvimento do interesse pela Matemática, Física e diversas outras disciplinas, oferecendo aos sujeitos um aprendizado interdisciplinar e significativo, além de permitir a interação entre os alunos no trabalho em equipe e propiciar um ambiente para a socialização dos conhecimentos e o desenvolvimento do pensamento lógicodedutivo.

\section{INTRODUÇÃO}

A difusão e multiplicação de diferentes Tecnologias da Informação e Comunicação (TIC) implicou em diversas transformações no cotidiano dos sujeitos, seja no lazer, no trabalho e no ensino, possibilitando novos métodos educacionais e visando atender as demandas das novas gerações. Castells (1999) defende que as transformações decorrentes da tecnologia na sociedade, contextualizadas por toda complexidade econômica e cultural, fez com que a tecnologia fosse a própria sociedade e que esta só pudesse ser compreendida por meio de suas ferramentas tecnológicas.

Observa-se então, que as tecnologias se expandiram e criaram inúmeras formas de interação social, seja em sites de relacionamentos virtuais ou aplicativos

\footnotetext{
${ }^{1}$ Graduando do Curso Superior de Licenciatura em Informática no Instituto Federal de Educação, Ciência e Tecnologia do Rio Grande do Norte (IFRN) - Campus Ipanguaçu. E-mail: laryssaclemente73@gmail.com

2 Professor Efetivo do Instituto Federal de Educação, Ciência e Tecnologia do Rio Grande do Norte (IFRN) - Campus Ipanguaçu. Mestre em Engenharia de Software. E-mail: alan.klinger@ifrn.edu.br
} 


\section{Laryssa Clemente E Alan Klinger}

móveis, que possibilitam interação e aprendizagem, como por exemplo, conhecer novas pessoas, seja como instrumento mediador no processo de ensino e aprendizagem, possibilitando motivação e estímulo aos sujeitos na construção do seu aprendizado.

Atualmente, ainda há um grande desinteresse por parte de muitos alunos, por qualquer atividade escolar. A maioria frequenta as aulas por obrigação e não participa das atividades. Ficam apáticos diante de qualquer iniciativa dos professores, que se confessam frustrados por não conseguirem atingir totalmente seus objetivos, conforme demonstrou a pesquisa realizada pelo MEC - Portal Brasil:

Em 2012, a taxa de abandono escolar atingiu 24,3\%. E o índice se torna ainda mais preocupante se comparado com países vizinhos, como Chile $(2,6 \%$ de evasão), Argentina (6,2\%) e Uruguai $(4,8 \%)$. Entre 1,6 milhão de alunos do ensino básico que abandonaram a escola, mais de 1,5 milhão cursava a rede pública, tanto no nível fundamental (762 mil) quanto no médio (760 mil). (BRASIL: Abandono Escolar, 2013 apud MORALES; ALVES, 2016).

Diante dessa situação, este estudo tem por objetivo analisar a implementação de um projeto de robótica educacional na escola Estadual Manoel de Melo Montenegro de ensino integral, do município de Ipanguaçu/RN, considerando a constituição de práticas pedagógicas interdisciplinares e a participação ativa dos professores.

Uma vez que o projeto esteja em andamento, se proporcionaria um ambiente de aprendizagem com fomento ao raciocínio, à criatividade e à construção. Permitindo uma aprendizagem interativa e lúdica, promovendo postura interdisciplinar e fomento à responsabilidade coletiva e particular. Castilho (2002) diz que, através do uso da robótica, podem-se criar mais possibilidades do desenvolvimento de diversas inteligências, e que a realização de atividades a partir de situações concretas pode motivar os alunos e consolidar o aprendizado.

Com isso é importante enfatizar o potencial interativo que o uso das tecnologias digitais possibilita ao aluno, tanto na ampliação dos seus conhecimentos, como também no estímulo, na qual o sujeito poderá integrar e interagir com os objetos de estudo, permitindo aprender por meio dessa ação.

Para Kupfer (1995, p. 79), “... o processo de aprendizagem depende da razão que motiva a busca de conhecimento", ou seja, os alunos precisam ser provocados para que sintam a necessidade de aprender. Apesar de muitas escolas públicas disponibilizarem computadores e recursos tecnológicos em suas dependências, muitas atividades desenvolvidas com o uso destes, fogem totalmente dos reais interesses dos alunos. Por isso, é fundamental que o professor juntamente com a escola estude e conheça essas ferramentas a fim de utilizá-las como auxílio nas aulas e não apenas usar por usar. Trata-se, na verdade, do processo de construção do conhecimento transformando a aprendizagem mais significativa, lúdica e interativa. 
A palavra interação diz respeito a uma ação recíproca que tem mútua influência nos elementos inter-relacionados. Para Silva (2000 apud Santana; Braga, 2016, p. 2) a interatividade possibilita que o espectador ultrapasse a condição de passivo para ativo, explicite o diálogo entre emissão e recepção, a criação conjunta da comunicação e a intervenção do usuário. Desse modo, não basta apenas que as tecnologias expliquem o conteúdo, mas elas devem ser estudadas, pensadas e projetadas de forma a ensinar aos alunos de forma lúdica, proporcionando um ensino no qual os alunos sejam capazes de pensar de forma crítica e reflexiva, visando a uma aprendizagem significativa.

Como justificativa considera-se que o domínio de conhecimentos sobre robótica seja capaz de fornecer inúmeras condições para o professor criar, avaliar e transformar sua prática em sala de aula, caracterizando o uso da tecnologia não somente como uma ferramenta, mas como uma ciência constituinte pautada na autonomia docente.

Com uma proposta pautada em uma discussão sobre a aprendizagem a partir da experiência com jogos digitais e seus benefícios, não só para alunos, mas também para a escola e professores, Rodrigues e Valadares (2013) mostram que existe um grande potencial para o uso de jogos como ferramentas nos processos de ensino e aprendizagem de línguas, já que a interação nos jogos, tanto entre jogadores quanto com os softwares ou a máquina, se dão por meio de linguagens.

Esses autores também evidenciam a questão da aprendizagem situada que é "capaz de ampliar em nossos alunos mais do que habilidades técnicas, fomentar capacidades cognitivas, afetivas, comunicacionais para que eles enfrentem esse mundo em constante transformação" (RODRIGUES; VALADARES, 2013, p. 58).

Diante disso a robótica educativa vem conquistando espaços significativos por ser considerada uma ciência interdisciplinar que possibilita um conhecimento de forma mais completa.

Segundo Fazenda (1979), a interdisciplinaridade é a atitude positiva diante do conhecimento, que implica mudança comportamental diante da tomada de decisões. Para ela, a interdisciplinaridade promove cooperação, trabalho, diálogo entre as pessoas, entre as disciplinas e entre outras formas de conhecimento.

Esse diálogo entre sujeitos e disciplinas, permite ao professor diferentes formas de ensinar, propiciando ao sujeito desenvolver ações para cotidiano, além de ser um facilitador no processo de ensino, gerando uma grande oportunidade de melhoria nos métodos e nas técnicas de um modelo mais convencional.

\section{DESENVOLVIMENTO}

Em um contexto permeado pelas tecnologias digitais, a educação lança discussões a respeito da integração e da necessidade de inserção das novas tecnologias como meios de ensino e aprendizagem, a fim de preparar o sujeito e incluí-lo nesse ambiente de conhecimento e informação, criando, assim, um espaço de possibilidades e novas experiências, visto que a sociedade se atualiza dia após dia. 


\title{
Laryssa Clemente $\mathcal{E}$ Alan Klinger
}

Lima (2006) nos faz perceber que o impacto dessas tecnologias no âmbito social, cultural e educacional vem assumindo um papel fundamental na construção e continuidade do conhecimento, a fim de contribuir diretamente nos processos de ensino e aprendizagem dos sujeitos e na inclusão destes no universo digital. (LIMA, 2006 apud COSTA; SOUZA, 2017, p. 226).

As tecnologias na educação ampliam as possibilidades de o professor ensinar e o aluno aprender. Percebe-se que, quando aplicadas de forma adequada, tendem a contribuir de forma positiva no processo educacional. Libâneo (1994, p. 309) firma que "o grande objetivo das escolas é a aprendizagem dos alunos, e a organização escolar necessária é a que leva a melhorar a qualidade dessa aprendizagem".

O desafio da escola, portanto, é saber como integrar as tecnologias à educação para que elas venham contribuir nos processos de ensino e aprendizagem, a fim de despertar a curiosidade, o estímulo dos sujeitos e prepará-los para um contexto social informatizado em que os conhecimentos adquiridos permitem as relações humanas, conforme evidência Moran,

\begin{abstract}
ensinar com as novas tecnologias será uma revolução se mudarmos simultaneamente os paradigmas convencionais do ensino, que mantêm distantes professores e alunos. Caso contrário, conseguiremos dar um verniz de modernidade, sem mexer no essencial (MORAN, 2000, p. 63).
\end{abstract}

É de se esperar que a escola tenha que se reinventar para atender às necessidades dos indivíduos e da sociedade, a fim de proporcionar aos sujeitos as atribuições desse recurso para a construção da vida social e a interação dos processos de comunicação e aprendizagem, legitimando as práticas cotidianas que constituem a cultura e associando-as de maneira interdisciplinar.

A interdisciplinaridade não é apenas reunir diferentes disciplinas. Trata-se de tornar as disciplinas comunicativas entre si. Segundo Fazenda et al (2002), o pensar interdisciplinar parte da argumentação de que nenhuma forma de conhecimento é em si mesma racional. Por isso, promover o diálogo com outras formas de conhecimento se torna essencial, pois permite a socialização de diferentes contextos e conteúdos atrelando por meio desse diálogo o conhecimento científico.

O termo interdisciplinaridade surgiu por volta dos anos 1920, significando a prática de interações entre fronteiras disciplinares. A questão principal da interdisciplinaridade está na possibilidade da existência da unidade do conhecimento. Ela ocupa uma posição intermediária entre a multi e a transdisciplinaridade, com o fato da ocorrência de trocas e enriquecimentos mútuos entre diferentes disciplinas, conforme afirma Fazenda (1993, p. 1): “voltada para a formação do indivíduo, a interdisciplinaridade propõe a capacidade de dialogar com as diversas ciências, fazendo entender o saber como um e não partes, ou fragmentações".

Nesse contexto, a interdisciplinaridade surge para facilitar e promover o conhecimento de forma mais completa, já que no ensino tradicional não propicia essa junção, ou seja, as disciplinas acontecem de forma fragmentada na medida em que 


\section{Laryssa Clemente \& Alan Klinger}

não se explora a relação entre os conhecimentos disciplinares, assim também como não há nenhum tipo de cooperação entre as disciplinas. Para Carlos,

\footnotetext{
Trata-se de uma prática que não dilui as disciplinas no contexto escolar, mas que amplia o trabalho disciplinar na medida em que promove a aproximação e a articulação das atividades docentes numa ação coordenada e orientada para objetivos bem definidos (CARLOS, 2006, p.7).
}

Atualmente, podemos observar a realidade escolar em uma situação de desânimo dos professores e o desestímulo que acompanham os alunos. Os processos de ensino e aprendizagem se mostram precários diante a uma totalidade, que seria o entendimento de nossa realidade e uma sociedade informatizada.

O contexto histórico vivido nessa era da sociedade da informação, na qual se caracteriza pela divisão do trabalho intelectual, fragmentação do conhecimento e pela excessiva influência das especializações, demanda a necessidade de romper com a tendência fragmentadora e desarticulada dos processos de ensino e aprendizagem, justificando-se pela compreensão da importância da interação e transformação recíprocas entre as diferentes áreas do saber.

Segundo Carlos (2006), é por meio da interdisciplinaridade que se promove a mobilização da comunidade escolar em torno de objetivos educacionais mais amplos. Portanto, para que isso ocorra, é necessário promover, em termos de prática docente, a associação entre diferentes disciplinas, assim, a tecnologia gera possibilidades de interação entre os sujeitos, conhecimento e produção de conteúdo, na qual se cria uma prática pedagógica que articula interdisciplinaridade e tecnologia.

A robótica é uma ciência tecnológica que se caracteriza por relacionar fortemente diferentes áreas técnicas, como a mecânica, cinemática, automação, hidráulica, informática, inteligência artificial, além disso, ela é uma ciência multidisciplinar, pois, permite uma relação entre as áreas de exatas, humanas e biociências.

Robótica não é só programação, como ressalta Quintanilha (2008 apud Guedes; Kerber, 2010, p. 201) e, sim, uma área generalista que pode combinar e ser combinada em áreas multidisciplinares, que integram disciplinas, como "a Matemática, Ciências, Língua Portuguesa, Expressões dramáticas" (RIBEIRO, 2006 apud Guedes; Kerber, 2010, p. 201). Esse conjunto múltiplo possibilita o desenvolvimento do senso crítico, a capacidade de observação, o pensamento dedutivo, as pesquisas e estratégias de comunicação como também a resolução de problemas. No geral, a área da robótica trata do desenvolvimento de sistemas compostos por máquinas automáticas e controladas por circuitos integrados programáveis.

Para Garcia et al. (2007, p. 20), a área da robótica se desenvolveu embasada na necessidade de encontrar soluções adequadas para demandas técnicas, tais como: acesso a ambientes confinados, reabilitação de pacientes etc. No entanto, a rápida evolução e sofisticação permitiu a pesquisa e aplicação em diversas outras áreas da sociedade, inclusive no âmbito educacional, apoiando os processos de ensino e de aprendizagem nos diversos níveis educacionais, englobando de forma 
interdisciplinar diferentes áreas, a fim de possibilitar o conhecimento técnico, juntamente com o conhecimento curricular.

Conforme Menezes e Silva (2015 apud PINTO, 2019), a definição de robótica educacional pode ser entendida como um termo utilizado para caracterizar os ambientes de aprendizagem que reúnem materiais de sucata ou kits de montagem compostos por peças diversas, motores e sensores controláveis por computador e softwares que permitam programar de alguma forma o funcionamento dos modelos montados.

No âmbito educacional, a Robótica Educativa ou Pedagógica é assim denominada, pois, segundo Gomes (2007, p. 130), ela "estimula a criatividade dos alunos devido a sua natureza dinâmica, interativa e até mesmo lúdica, além de servir de motivador para estimular o interesse dos alunos no ensino tradicional."

Podemos perceber que o processo de aprendizagem idealizado por Piaget $e t$ al. (1973, p.70) ocorre dentro da robótica educacional, porém a base piagetiana de desenvolvimento não considera a interferência do outro (COLL et al., 1994), na qual considera o aluno como construtor do seu próprio saber, que interage e produz o seu próprio aprendizado, estabelecendo uma relação de troca com o meio e o objeto. Essa relação possibilita uma aprendizagem mais ativa e participativa permitindo ao aluno um processo de construção de conhecimento significativo na assimilação dos conteúdos estudados.

O conhecimento resultaria de interações que se produzem entre o sujeito e objeto. A troca inicial entre sujeito/objeto se daria a partir da ação do sujeito. Logo, não existe conhecimento resultante do simples registro de observações e informações, sem uma estrutura devida às atividades do próprio sujeito (PIAGET, 1973).

Todavia, na robótica isso pode acontecer de outra maneira, por meio da interação entre professor e aluno, e principalmente, entre alunos. A robótica educacional tem como condição a relação entre os sujeitos, concebendo o desenvolvimento entre os iguais.

Segundo Seymour Papert (1980 apud Paiva; Galvão; Paiva, 2018, p. 25), a robótica educacional refere-se ao "aprender-fazendo", na qual são apresentados esquemas e estruturas cognitivas, construídas de acordo com a vivência dos indivíduos, em que eles aprendem melhor quando são envolvidos no planejamento e construção dos objetos, considerando-os mais significativos. Assim, a utilização desse recurso leva o aluno a ir além da simples observação, do aprendizado abstrato, e sua prática possibilita uma aprendizagem dinâmica e significativa por meio da contextualização e problematização.

O papel da robótica, de acordo com Cambruzzi e Souza (2013, p. 42), “é estimular os alunos a trabalharem colaborativamente na montagem de mecanismos e na programação de ações para o funcionamento do seu sistema, priorizando a socialização, trabalho em equipe e o aprendizado que reúne ciência e tecnologia". 
A utilização desse recurso no âmbito educacional ajuda na mudança dos processos de ensino e aprendizagem, na qual o aluno busca por meio do jogo o conhecimento na disciplina, e o professor é o mediador neste processo, contribuindo de forma significativa no desenvolver dos conteúdos nas disciplinas, utilizando-se da imaginação e criatividade pautadas em experiências práticas.

Segundo Vygotsky (1998) a aprendizagem é baseada principalmente no relacionamento das pessoas e caracteriza a mudança de comportamento, pois desenvolve habilidades. A robótica educacional possibilita competências que são desenvolvidas a partir da interação entre os sujeitos, através da montagem e utilização de protótipos robóticos, que são mediados com o auxílio do professor.

\section{ASPECTOS METODOLÓGICOS}

Foi realizada uma pesquisa bibliográfica que teve o objetivo de unir informações teóricas que serviram de base para a construção dessa pesquisa. É definida por Laville e Dionne (1999, p.168) como uma coleta de informações que se resume em reunir documentos, em descrever ou transcrever eventualmente seu conteúdo e efetuar uma primeira ordenação das informações para selecionar aquelas que parecem pertinentes.

Utilizou-se o estudo de campo que propiciou observar as dificuldades dos alunos e também o que mais o desmotivam no ambiente escolar a fim de analisá-los. Segundo Gil (2008, p.57), os estudos de campo procuram muito mais o aprofundamento das questões de uma realidade específica; tendem a utilizar mais técnicas de observação do que de interrogação, pois é por meio da observação das atividades do grupo estudado e de entrevistas com informantes que se captarão as explicações e interpretações do que ocorrem naquela realidade. O estudo de campo foi desenvolvido na escola estadual Manoel de Melo Montenegro que oferece o ensino médio em tempo integral, localizada na cidade de Ipanguaçu/RN.

Neste estudo de campo foi proposto utilizar a observação participante que de acordo com Severino (2007), é aquela que o pesquisador compartilha a vivência dos sujeitos pesquisados, participando de forma sistemática, passando a interagir com eles em todas as situações, acompanhando todas as ações praticadas pelos sujeitos e buscando, a partir destas, todos os elementos e considerações ao longo dessa participação. Ou seja, a partir dessa observação, o observador pode estar totalmente inserido no cenário de estudo, participando dessa realidade e percebendo quais as dificuldades dos sujeitos, promovendo a criação de formas de ensino a partir dessas dificuldades percebidas diante da observação.

\section{CONSIDERAÇÕES FINAIS}

Com essa pesquisa, buscou-se mostrar que o uso da Robótica Educacional, no ensino, pode estimular a curiosidade dos sujeitos e consequentemente a participação deles na construção de uma aprendizagem mais significativa. E diante disso, 


\section{Laryssa Clemente $\mathcal{E}$ Alan Klinger}

evidenciar que ferramentas lúdicas contribuem para o desenvolvimento da aprendizagem.

A Robótica Educacional aplicada ao estudo de outras disciplinas estabelece uma situação propícia ao trabalho interdisciplinar entre estes componentes curriculares, além do diálogo. Portanto, esse recurso didático pode proporcionar que professores e alunos vivenciem momentos de interdisciplinaridade. Além disso, o estudo dessa ciência favorece aos alunos maior engajamento e motivação para participar mais ativamente da vida escolar, além do entusiasmo.

Para os professores, a robótica na escola ajudará a estabelecer aulas mais práticas, possibilitando mais interação entre o ensino tradicional e o ensino voltado para a tecnologia, e dessa forma promover mais comunicação e autonomia entre o corpo docente e mobilização de conhecimento das diversas áreas disciplinares envolvidas. Apesar do uso da robótica não ser novidade na área educacional, ainda é pouco utilizada nas escolas e cabe aos professores buscar e incluir em suas aulas esse novo meio de ensinar.

Com isso, espera-se que os professores utilizem essa proposta como uma nova forma de buscar atração à atenção do aluno para o estudo das disciplinas, deixando o método convencional de ensino e utilizando-a em diferentes contextos e disciplinas.

\section{REFERENCIAS}

CAMBRUZZI, Eduardo. SOUZA, Rosemberg M. O uso da Robótica Educacional para o Ensino de Algoritmos. 2013. Disponível em: <http:/ / www.eati.info/2014/assests/anais/artigo.pdf>. Acesso em 17 abril.2018.

CARLOS, Jairo Gonçalves. Interdisciplinaridade no Ensino Médio: desafios e potencialidades. Programas de Pós-graduação da CAPES. 2006. Disponível em:< www.unb.br/ppgec/dissertacoes/.../proposicao_jairocarlos.pdf> Acesso em: 09 de junho de 2018.

CASTELLS, M. (1999). A Sociedade em Rede (Vol. I, 14ª ed.). São Paulo: Paz e Terra

CASTILHO, M. I. Robótica na educação: com que objetivos? 2002. Dissertação (Mestrado) Universidade Federal do Rio Grande do Sul, Porto Alegre, 2002.

COLL, C. Aprendizagem escolar e construção do conhecimento. Porto Alegre: Artes Médicas Sul, 1994.

COSTA, Maiara Capucho; SOUZA, Maria Aparecida Silva de. O uso das Tics no processo ensino e aprendizagem na Escola Alternativa "Lago dos Cisnes". 2017. Disponível em: <https://revistavalore.emnuvens.com.br/valore/article/view/70/66>. Acesso em: 04 nov. 2019. 
FAZENDA, I. C. A. Integração e interdisciplinaridade no ensino brasileiro: efetividade ou ideologias. 5.ed. São Paulo: Edições Loyola, 2002.

FAZENDA, I. Integração e interdisciplinaridade no ensino brasileiro: efetividade ou ideologia. $4^{a}$ ed. São Paulo: Loyola, 1979.

FAZENDA, Ivani. A Interdisciplinaridade: um projeto em parceria. São Paulo: Loyola, 1993.

GARCIA et al. 2007. Garcia, E., Jimenez, M., De Santos, P., and Armada, M. (2007). The Evolution of Robotics Research. IEEE Robotics and Automation Magazine, 90103, 2007.

GIL, Antônio Carlos. Como elaborar projetos de pesquisas. 4. ed. São Paulo: Atlas, 2002. 173 p. Disponível em: <http://www.urca.br/itec>. Acesso em: 28 ago. 2019.

GIL, Antônio Carlos. Dados e Técnicas de pesquisa social. 6. ed. São Paulo: Atlas, 2008. $220 \mathrm{p}$.

GOMES, Nilma Lino. Diversidade e Currículo. Brasil/Mec, Brasília, 2007.

KUPFER, Maria Cristina. Freud e a Educação - O mestre do impossível. São Paulo: Scipione, 1995.

LAKATOS, Eva Maria; MARCONI, Marina Andrade. Fundamentos de Metodologia Científica. 3. ed. São Paulo: Atlas, 2004.

LAVILLE, Christian; DIONNE, Jean (Comp.). A construção do saber: Manual de metodologia da pesquisa em ciências humanas. Porto Alegre: Artmed, 1999.

LIBÂNEO, José Carlos. Didática. São Paulo: Editora Cortez, 1994.

MORALES, Marcia de Lourdes; ALVES, Fábio Lopes. O desinteresse dos alunos pela aprendizagem: Uma intervenção pedagógica. 2016. Disponível em: <http://www.diaadiaeducacao.pr.gov.br/portals/cadernospde/pdebusca/produco es_pde/2016/2016_artigo_ped_unioeste_marciadelourdesmorales.pdf $>$. Acesso em: 30 out. 2019.

MORAN, José Manuel et al. Novas tecnologias e mediação pedagógica. 6. ed. Campinas: Papirus, 2000. 


\section{Laryssa Clemente $\mathcal{E}$ Alan Klinger}

PAIVA, Kleison S.; GALVÃO, Angel P.; PAIVA, Ilarilda D. A. Robótica educacional no ensino-aprendizado de matemática na educação básica de Santarém-PA. 2018. Disponível

em: <https://www.researchgate.net/profile/Angel_Galvao/publication/323816485_Rob otica_educacional_no_ensino-

aprendizado_de_matematica_na_educacao_basica_de_Santarem-PA.pdf $>$. Acesso em: 09 out. 2019.

PIAGET, J. (1973). A linguagem e o pensamento da criança. 3ed. Rio de Janeiro: Editora Fundo de Cultura

PINTO, Carlos Alberto Schettini. A gestão do conhecimento e a inteligência colaborativa em ambientes de aprendizagem :um estudo a partir da oficina de robótica educacional no Colégio Militar do Rio de Janeiro. 2019. Disponível em: <http://www.DissertaoSchettini_comfichabibliogrficaeassinatura>. Acesso em: 13 set. 2019 .

QUINTANILHA, Leandro. Irresistível robô. Revista A Rede, São Paulo, ano 3, n. 34, p.10-17, mar. 2008.

RIBEIRO, Célia Rosa. Robô Carochinha: Um Estudo Qualitativo sobre a Robótica Educativa no $\mathbf{1}^{\mathbf{0}}$ ciclo do Ensino Básico. 2006. 189 f. Dissertação Mestrado em Educação Tecnologia Educativa- Universidade do Minho, Braga, 2006. Disponível em: <http:// repositorium.sdum.uminho.pt/ bitstream/1822/6352/2/teseRoboticaCeliari beiroFinal.pdf>Acesso em: 30 out. 2019.

RODRIGUES, C. A.; VALADARES, M.G.P. Princípios de aprendizagem de jogos eletrônicos: Gameficando a aula de línguas. Revista Horizontes de Linguística Aplicada, v. 12, p. 41-61, 2013.

SANTANA, Eber da Silva de; BRAGA, Francisco Renato do N. A usabilidade da plataforma Arduino na área didática como ensino e aprendizagem: um estudo de caso em uma instituição de ensino superior em Salvador/BA. 2016. Disponível em: <https://www.editorarealize.com.br/revistas/conedu/trabalhos>. Acesso em: 08 ago. 2018.

SEVERINO, Antônio Joaquim. Metodologias do Trabalho científico. 23. ed. São Paulo: Cortez Editora, 2007. 303 p.

VYGOTSKY, Lev S. A formação social da mente. $4^{\mathrm{a}}$ ed. São Paulo: Loyola 1998. 